\title{
Karateristik Distribusi Frekuensi Ibu Pascamelahirkan dengan Kejadian Postpartum Blues Bandar Lampung 2019
}

\author{
Fonda Octarianingsih ${ }^{1}$, Festy Ladyani ${ }^{2}$, Woro pramesti ${ }^{3}$, Nahlah Fathin Nabilah ${ }^{4}$ \\ ${ }^{1)}$ Departemen Obstetri ginekologi, Fakultas Kedokteran Universitas Malahayati, fondashariff@gmail.com \\ ${ }^{2)}$ Departemen Gizi, Fakultas Kedokteran Universitas Malahayati, mladyani@gmail.com \\ ${ }^{3)}$ Departemen Ilmu Kejiwaan Fakultas Kedokteran Universitas Malahayati, woropramesti@gmail.com \\ ${ }^{4)}$ Fakultas Kedokteran Universitas Malahayati,nahlahfathinn@gmail.com
}

\begin{abstract}
ABSTRAK
Postpartum blues adalah suasana hati yang dirasakan oleh wanita setelah melahirkan yang berlangsung selama 36 hari dalam 14 hari pertama pascamelahirkan, di mana perasaan ini berkaitan dengan bayinya (Mansur, 2009 : 156). Tujuan dari penelitian ini adalah mengetahui distribusi frekuensi ibu pascamelahirkan dengan kejadian postpartum blues di Puskesmas Rawat Inap Kemiling dan Praktik bidan kecamatan kemiling Bandar Lampung, dan Mengetahui karateristik distribusi frekuensi ibu pascamelahirkan dengan kejadian postpartum blues di Puskesmas Rawat Inap Kemiling dan Praktik bidan kecamatan kemiling Bandar Lampung. Jenis penelitian yang digunakan dalam penelitian ini adalah deskriptif kuantitatif. Sampel yang digunakan pada penelitian ini dengan sampling minimal 30 ibu postpartum di Puskesmas Rawat Inap Kemiling dan praktik bidan kecamatan Kemiling. Hasil dari penelitian yang dilakukan di Puskesmas Rawat Inap Kemiling dan praktik bidan kecamatan Kemiling Bandar Lampung untuk Distribusi frekuensi kejadian postpartum blues didapatkan ibu yang mengalami postpartum blues berjumlah 6 responden (14,6\%) dan ibu yang tidak mengalami postpartum blues berjumlah 35 responden ( 85 , 4\%). Sehingga diketahui bahwa dari 41 ibu postpartum sebagian besar tidak mengalami postpartum blues. Kejadian postpartum blues di puskesmas rawat inap Kemiling dan bidan Kecamatan Kemiling yaitu 14,6\% dan Sebagian besar karateristik responden umur 21-35 tahun, multipara, pervaginam, pendidikan rendah, bekerja, berpenghasilan $>U M R$.
\end{abstract}

Kata Kunci: Postpartum Blues, Pascamelahirkan, Bandar Lampung

\section{ABSTRACT}

Postpartum blues is a mood felt by women after childbirth, which lasted for 3-6 days in the first 14 days postpartum, which is related to the baby's feelings (Mansur, 2009: 156). Objective: This study aimed to determine the distribution frequency of postpartum mothers with postpartum blues case in Puskesmas Kemiling and midwife clinic in sub-district of Kemiling, Bandar Lampung Midwife Sub-district Practices in Bandar Lampung. This study also aimed to know the characteristics of postpartum maternal frequency distribution with postpartum blues incidents in the Puskesmas Inpatient Center and Midwife Practices in Bandar Lampung sub-district. The type of research used in this study was quantitative descriptive. The sample used at least 30 postpartum mothers in Puskesmas Kemiling and midwife clinics in Kemiling. The results of research conducted in Puskesmas Kemiling and midwife clinics Kemiling Bandar Lampung for the frequency distribution of the postpartum blues cases, it is found that mothers who experienced postpartum blues were about 6 respondents (14,6\%) and mothers who did not experience postpartum blues were about 35 respondents $(85,4 \%)$. It is known that from 41 postpartum mothers, most of them did not experience postpartum blues. The postpartum blues cases in Puskesmas Kemiling and midwife clinics Kemiling were at 14,6\%. Most of respondents were aged 21-35 years old, multiparous, vaginal, low education, work, income above regional minimum wage.

Keywords: Postpartum Blues, Post-partum, Bandar Lampung

* Korespondensi Author: Nahlah fathin nabilah, Universitas Malahayati, @nahlahfathinn@gmail.com,

\section{PENDAhuluan}

Proses adaptasi psikologi pada seorang ibu sudah di mulai sejak hamil. Kehamilan dan persalinan merupakan peristiwa yang normal terjadi dalam hidup, namun banyak ibu yang mengalami stress yang signifikan. Ada kalanya ibu mengalami perasaan sedih yang berkaitan dengan bayinya, keadaan ini disebut postpartum blues atau baby blues. Secara psikologis, seorang ibu akan merasakan gejala-gejala psikis 
setelah melahirkan. Beberapa penyesuaian dibutuhkan oleh wanita yang tengah mengalami masa melahirkan baik secara fisik maupun psikis. ${ }^{1,2}$

Sebagian wanita ada yang berhasil menghadapi hal tersebut dan ada pula sebagian yang tidak bisa menyesuaikan diri, bahkan bagi mereka yang tidak dapat menyesuaikan diri mereka mengalami gangguan-gangguan psikologis dengan berbagai macam syndrom atau gejala yang oleh para peneliti disebut dengan postpartum blues. Postpartum blues adalah suasana hati yang dirasakan oleh wanita setelah melahirkan yang berlangsung selama 3-6 hari dalam 14 hari pertama pascamelahirkan, di mana perasaan ini berkaitan dengan bayinya. Postpartum blues merupakan salah satu bentuk gangguan perasaan akibat penyesuaian terhadap kelahiran bayi, yang muncul pada hari pertama sampai hari ke empat belas setelah proses persalinan, dengan gejala memuncak pada hari ke lima. ${ }^{2,3,4}$

Postpartum blues ini dikategorikan sebagai sindrom gangguan mental yang ringan. Oleh sebab itu, gangguan ini sering tidak dipedulikan bahkan sering dianggap sebagai efek samping dari keletihan, sehingga tidak terdiagnosis dan tidak tertangani sebagaimana harusnya. Apabila postpartum blues tidak ditangani dengan serius, maka akan berkembang menjadi depresi postpartum dan kondisi yang paling berat bisa sampai postpartum psychosis ${ }^{4}$.

Postpartum blues sering menyebabkan terputusnya interaksi antara ibu dan anak, dan mengganggu perhatian dan bimbingan yang dibutuhkan bayinya untuk berkembang secara baik. Data dari penelitian di seluruh dunia secara tegas menunjukkan bahwa sekitar 50-75\% wanita mengalami postpartum blues. Di Belanda tahun 2001 diperkirakan 2-10\% ibu melahirkan mengidap gangguan ini. $3,4,5$

Penelitian yang dilakukan terhadap 154 wanita pascamelahirkan di Malaysia pada tahun 2009 dilaporkan angka kejadian 3,9\% terbanyak dari ras India $(8,9 \%)$, Melayu $(3,0 \%)$, dan tidak adanya kasus pada ras Cina. Penelitian di Singapura pada tahun 2009 dilaporkan angka kejadiannya sebesar $1 \%$, sedangkan penelitian pada tahun 2010 sekitar 10\%-20\%. Pelaporan prevalensi kejadian postpartum blues bervariasi diserluruh dunia. Prevalensi di Indonesia yaitu 50-70\%, satu dari sepuluh wanita yang baru saja melahirkan memiliki kecenderungan postpartum blues. $^{6}$

Penelitian yang dilakukan di Bps Amrina, Amd.Keb Kelurahan Ganjar Asri Kecamatan Metro Barat Kota Metro oleh utami menyatakan bahwa diketahui bahwa dari 60 responden dengan postpartum kelompok kasus sebanyak 20 orang $(33,3 \%)$ dan kelompok kontrol sebanyak 40 orang $(66,7 \%)^{1}$. Berdasarkan latar belakang tersebut penulis tertarik melakukan penelitian untuk mengetahui distribusi frekuensi ibu pascamelahirkan dengan kejadian postpartum blues di Puskesmas Rawat Inap Kemiling dan praktik bidan kecamatan kemiling Bandar Lampung tahun 2019. Penelitian dilakukan di puskesmas rawat inap Kemiling dan praktik bidan kecamatan Kemiling dikarnakan angka paritas di kecamatan kemiling cukup tinggi.

\section{METODOLOGI}

Penelitian ini menggunakan jenis kuantitatif karena data diperoleh melalui pengukuran terhadap fenomena dari subyek penelitian. Penelitian telah dilaksanakan pada bulan November - Desember tahun 2019. Tempat penelitian dilakukan pada Puskesmas Rawat Inap Kemiling dan praktik bidan kecamatan Kemiling Bandar Lampung. Populasi yang digunakan dalam penelitian ini adalah ibu postpartum 7-14 hari pada bulan November Desember 2019 di Puskesmas Rawat Inap Kemiling dan praktik bidan kecamatan Kemiling Bandar Lampung. Jumlah Sampel yang digunakan pada penelitian ini berjumlah $41 \mathrm{ibu}$ postpartum di Puskesmas Rawat Inap Kemiling dan praktik bidan kecamatan Kemiling. Analisis data yang digunakan adalah chi-square dan Teknik sampling yang digunakan pada penelitian ini adalah total sampling dari kasus kejadian postpartum blues pada ibu postpartum 7-14 hari di Puskesmas Rawat Inap Kemiling dan praktik bidan kecamatan Kemiling.

III. HASIL DAN PEMBAHASAN 
Data yang digunakan pada penelitian ini adalah data hasil pengisian kuesioner oleh ibu postpartum 7-14 hari pada bulan November Desember 2019 di Puskesmas Rawat Inap Kemiling dan praktik bidan kecamatan Kemiling Bandar Lampung.

Tabel 1. Distribusi Frekuensi Kejadian Postpartum Blues

\begin{tabular}{ccc}
\hline $\begin{array}{c}\text { Kejadian } \\
\text { postpartum blues }\end{array}$ & Jumlah & Presentasi \% \\
\hline Postpartum blues & 6 & $14,6 \%$ \\
Normal & 35 & $85,4 \%$ \\
\hline Total & 41 & $100 \%$ \\
\hline
\end{tabular}

Pada tabel 1 menunjukkan bahwa sebagian besar ibu yang tidak mengalami postpartum blues dengan jumlah 35 responden $(85,4 \%)$. Sehingga diketahui bahwa dari 41 ibu postpartum sebagian besar tidak mengalami postpartum blues. Dimana untuk kejadian postpartum blues di puskemas rawat inap Kemiling dan praktik bidan kecamatan Kemiling pada kasus tersebut rendah.

Tabel 2. Distribusi Frekuensi Umur Responden

\begin{tabular}{ccc}
\hline Umur & Jumlah & Persentase\% \\
\hline $\begin{array}{c}\text { <21tahun dan } \\
\text { >35tahun }\end{array}$ & 10 & $24,4 \%$ \\
$21-35$ tahun & 31 & $75,6 \%$ \\
\hline Total & 41 & $100 \%$ \\
\hline
\end{tabular}

Pada tabel 2 didapatkan bahwa distribusi frekuensi karateristik responden berdasarkan umur, didapatkan umur $<21$ tahun dan >35tahun tahun berjumlah 10 responden (24,4\%), sedangkan 21-35 tahun didapatkan 31 responden $(75,6 \%)$. Sehingga diketahui bahwa dari 41 ibu postpartum sebagian besar berusia 21-35 tahun. adalah pada rentang usia 21-35 tahun.

Tabel 3. Distribusi Frekuensi Paritas Responden

\begin{tabular}{ccc}
\hline Paritas & Jumlah & Persentase \% \\
\hline Primipara & 9 & $22 \%$ \\
Multipara & 32 & $78 \%$ \\
\hline Total & 41 & $100 \%$ \\
\hline
\end{tabular}

Pada tabel 3 didapatkan bahwa distribusi frekuensi karateriktik responden berdasarkan paritas, didapatkan primipara berjumlah 9 responden (22\%), sedangkan multipara berjumlah 32 responden (78\%). Sehingga diketahui bahwa dari 41 ibu postpartum sebagian besar multipara. Artinya sebagian besar responden memiliki anak lebih dari dua.

Tabel 4. Distribusi Frekuensi Persalinan Responden

\begin{tabular}{ccc}
\hline Persalinan & Jumlah & Persentase $\%$ \\
\hline Sesar & 9 & $22 \%$ \\
Pervaginam & 32 & $78 \%$ \\
\hline Total & 41 & $100 \%$ \\
\hline
\end{tabular}

Pada tabel 4 didapatkan bahwa distribusi frekuensi karakteristik responden berdasarkan persalinan didapatkan, sesar berjumlah 9 responden (22\%), sedangkan Pervaginam berjumlah 32 responden (78\%). Sehingga diketahui bahwa dari 41 ibu postpartum sebagian besar persalinannya melalui pervaginam. Dari hasil penelitian ini disebabkan karena pengambilan sampel di puskesmas dan praktik bidan sehingga responden sebagian besar melahirkan secara pervaginam.

Tabel 5. Distribusi Frekuensi Pendidikan

\begin{tabular}{ccc}
\multicolumn{3}{c}{ Responden } \\
\hline Pendidikan & Jumlah & Persentase \% \\
\hline Pendidikan tinggi & 10 & $24,4 \%$ \\
Pendidikan rendah & 31 & $75,6 \%$ \\
\hline Total & 41 & $100 \%$
\end{tabular}

Pada tabel 5 didapatkan bahwa distribusi frekuensi karakteristik responden berdasarkan pendidikan, didapatkan pendidikan tinggi berjumlah 10 responden $(24,4 \%)$, sedangkan pendidikan rendah berjumlah 31 responden (75,6\%). Sehingga diketahui bahwa dari $41 \mathrm{ibu}$ postpartum sebagian besar berpendidikan rendah. Dalam peneilitian ini yang dimaksud berpendidikan rendah adalah responden yang tidak bersekolah dan berpendidikan dibawah SMP/Sederajat. 
Tabel 6. Distribusi Frekuensi Pekerjaan

\begin{tabular}{ccc} 
& Responden & \\
\hline Pekerjaan & Jumlah & Persentase \% \\
\hline Bekerja & 25 & $61 \%$ \\
Tidak Bekerja & 16 & $39 \%$ \\
\hline Total & 41 & $100 \%$ \\
\hline
\end{tabular}

Pada tabel 6 didapatkan bahwa distribusi frekuensi karateristik responden berdasarkan pekerjaan. Data yang didapatkan tidak bekerja berjumlah 16 responden (39\%), sedangkan bekerja berjumlah 25 responden (61\%). Sehingga diketahui bahwa dari $41 \mathrm{ibu}$ postpartum sebagian besar bekerja.
Tabel 7. Distribusi Frekuensi Penghasilan Responden

\begin{tabular}{ccc}
\hline Penghasilan & Jumlah & Presentase $\%$ \\
\hline <UMR & 7 & $17,1 \%$ \\
>UMR & 34 & $82,9 \%$ \\
\hline Total & 41 & $100 \%$ \\
\hline
\end{tabular}

Pada Tabel 7 didapatkan bahwa distribusi frekuensi responden berdasarkan penghasilan. Data didapatkan <UMR berjumlah 7 responden (17,1\%), sedangkan >UMR berjumlah 34 responden (82,9\%). Sehingga diketahui bahwa dari 41 ibu postpartum sebagian besar $>\mathrm{UMR}$.

Tabel 8. Analisis Data Antara Umur Dengan Postpartum Blues

\begin{tabular}{|c|c|c|c|c|c|c|}
\hline \multirow{3}{*}{ Umur } & \multicolumn{4}{|c|}{ Postpartum blues } & \multicolumn{2}{|c|}{ Nilai } \\
\hline & \multicolumn{2}{|c|}{ Ya } & \multicolumn{2}{|c|}{ Tidak } & \multirow[b]{2}{*}{$\mathrm{P}$} & \multirow[b]{2}{*}{ OR } \\
\hline & $\mathrm{N}$ & $\%$ & $\mathrm{~N}$ & $\%$ & & \\
\hline \multirow[t]{2}{*}{$<21$ dan $>35$} & 4 & $40 \%$ & 6 & $60 \%$ & & $\begin{array}{l}9,667 \\
(1,429\end{array}$ \\
\hline & & & & & 0,024 & - \\
\hline $21-35$ & 2 & $6,5 \%$ & 29 & $93,5 \%$ & & $65,377)$ \\
\hline Total & 6 & $14,6 \%$ & 35 & $85,4 \%$ & & \\
\hline
\end{tabular}

Pada tabel 8 didapatkan bahwa dari $41 \mathrm{ibu}$ postpartum sebagian besar yang mengalami postpartum blues yaitu $<21$ tahun dan $>35$ tahun sebanyak 4 responden $(40 \%)$. Dengan nilai $\mathrm{p}$ sebesar 0,024 yang menunjukkan bahwa ada hubungan antara usia dengan kejadian postpartum blues. Ibu dengan usia $<21$ tahun dan $>35$ tahun mempunyai kemungkinan 9,667 kali mengalami postpartum blues. Faktor umur juga mempengaruhi terjadinya masalah psikologis pada ibu postpartum.

Secara umum pada usia remaja memiliki pengetahuan yang terbatas tentang kehamilan atau kurangnya informasi dalam mengakses pelayanan kesehatan yang ada. Selain itu pada usia tersebut juga belum cukup mencapai kematangan fisik, mental, peran dan aktivitas baru sebagai ibu dalam merawat anaknya. Semakin muda usia ibu melahirkan semakin mudah ibu mengalami postpartum blues. Hal yang berbeda penelitian yang dilakukan Irawati didapatkan bahwa umur yang mengalami postpartum blues adalah usia $<20$ tahun dan $>35$ tahun, usia tersebut merupakan usia berisiko bagi perempuan untuk melahirkan seorang bayi. Kondisi ini tidak sesuai dengan pendapat Bobak , bahwa faktor pencetus terjadinya postpartum blues adalah pada usia remaja atau kurang dari 20 tahun . $2,7,8$ 
Tabel 9. Analisis Data Antara Paritas Dengan Postpartum Blues.

\begin{tabular}{|c|c|c|c|c|c|c|}
\hline \multirow{4}{*}{ Persalinan } & \multicolumn{4}{|c|}{ Postpartum blues } & \multirow{2}{*}{\multicolumn{2}{|c|}{ Nilai }} \\
\hline & & & & & & \\
\hline & \multicolumn{2}{|c|}{$\mathrm{Ya}$} & \multicolumn{2}{|c|}{ Tidak } & \multirow[b]{2}{*}{$\mathrm{P}$} & \multirow[b]{2}{*}{ OR } \\
\hline & $\mathrm{N}$ & $\%$ & $\mathrm{~N}$ & $\%$ & & \\
\hline Sesar & 4 & $44,4 \%$ & 5 & $55,6 \%$ & & 12,000 \\
\hline Pervaginam & 2 & $6,2 \%$ & 30 & $93,8 \%$ & 0,015 & $(1,718-83,803)$ \\
\hline Total & 6 & $14,6 \%$ & 35 & $85,4 \%$ & & \\
\hline
\end{tabular}

Pada tabel 9 didapatkan bahwa dari 41 ibu postpartum sebagian besar yang mengalami postpartum blues yaitu primipara sebanyak 4 responden $(44,4 \%)$. Dengan nilai $\mathrm{p}$ sebesar 0,015 yang menunjukkan bahwa ada hubungan antara paritas dengan kejadian postpartum blues. Ibu dengan primipara mempunyai kemungkinan 12,000 kali mengalami postpartum blues. Postpartum blues dapat terjadi pada semua ibu postpartum dari suku dan ras manapun dan dapat terjadi pada ibu primipara maupun multipara. Hasil penelitian ini sejalan dengan penelitian sebelumnya yang dilakukan oleh sari priyanti menyatakan bahwa postpartum blues lebih banyak dialami oleh ibu dengan primipara dan penelitian Irawati didapatkan hasil penelitian bahwa sebagian besar responden yang mengalami postpartum blues adalah primipara yaitu 14 responde $(63,6 \%)$. ${ }^{9,10,11}$

Tabel 10. Analisis Data Antara Persalinan dengan Postpartum Blues

\begin{tabular}{ccccccc}
\hline \multirow{3}{*}{ Paritas } & \multicolumn{5}{c}{ Postpartum blues } \\
\cline { 2 - 6 } & \multicolumn{4}{c}{ Ya } & \multicolumn{3}{c}{ Tidak } & \multicolumn{2}{c}{ Nilai } \\
\cline { 2 - 6 } & $\mathrm{N}$ & $\%$ & $\mathrm{~N}$ & $\%$ & $\mathrm{P}$ & OR \\
\hline Primipara & 4 & $44,4 \%$ & 5 & $55,6 \%$ & 12,000 \\
Multipara & 2 & $6,2 \%$ & 30 & $93,8 \%$ & 0,015 & $(1,718-83,803)$ \\
& & & & & & \\
\hline Total & 6 & $14,6 \%$ & 35 & $85,4 \%$ & & \\
\hline
\end{tabular}

Pada tabel 10 didapatkan bahwa dari 41 ibu postpartum sebagian besar yang mengalami postpartum blues yaitu persalinan melalui sesar sebanyak 4 responden $(44,4 \%)$. Dengan nilai $\mathrm{p}$ sebesar 0,015 yang menunjukkan bahwa ada hubungan antara persalinan dengan kejadian postpartum blues. Ibu dengan persalinan sesar mempunyai kemungkinan 12,000 kali mengalami postpartum blues.Persalinan merupakan suatu peristiwa yang rumit dan dapat menimbulkan stres bagi seorang ibu, pendukung teori stres persalinan dapat merangsang reaksi untuk terjadinya postpartum blues. Hal ini pun sesuai dengan pendapat Henshaw bahwa penyulit persalinan berhubungan dengan terjadinya postpartum blues ${ }^{4}$. Hasil penelitian ini sejalan dengan penelitian Hasil penelitian yang disampaikan Ibrahim, dkk sebagian besar terdapat pada jenis persalinan patologis (caesaria) sebanyak 14 responden $(46,7 \%)$, sedangkan pada persalinan fisiologis (normal) hanya berjumlah 1 responden $(2,2 \%) .8,9$ 
Tabel 11. Analisis Data Antara Pendidikan Dengan Postpartum Blues.

\begin{tabular}{|c|c|c|c|c|c|c|}
\hline \multicolumn{7}{|c|}{ Postpartum blues } \\
\hline \multirow{2}{*}{ Pendidikan } & \multicolumn{2}{|c|}{$\mathrm{Ya}$} & \multicolumn{2}{|c|}{ Tidak } & \multicolumn{2}{|r|}{ Nilai } \\
\hline & $\mathrm{N}$ & $\%$ & $\mathrm{~N}$ & $\%$ & $\mathrm{P}$ & OR \\
\hline Pendidikan Tinggi & 4 & $40 \%$ & 6 & $60 \%$ & & 9,667 \\
\hline Pendidikan Rendah & 2 & $6,5 \%$ & 29 & $93,5 \%$ & 0,024 & $\begin{array}{c}(1,429- \\
65,377)\end{array}$ \\
\hline
\end{tabular}

\begin{tabular}{ccccc}
\hline Total & 6 & $14,6 \%$ & 35 & $85,4 \%$ \\
\hline
\end{tabular}

Pada tabel 11 didapatkan dari $41 \mathrm{ibu}$ postpartum sebagian besar yang mengalami postpartum blues yaitu pendidikan tinggi sebanyak 4 responden (40\%). Dengan nilai $\mathrm{p}$ sebesar 0,024 yang menunjukkan bahwa adanya hubungan antara pendidikan dengan kejadian postpartum blues. Ibu dengan pendidikan tinggi mempunyai kemungkinan 9,667 kali mengalami postpartum blues. Wanita yang berpendidikan tinggi menghadapi tekanan sosial dan konflik peran antara tuntunan sebagai wanita berpendidikan tinggi yang memiliki dorongan untuk bekerja dan melakukan aktivitas di luar rumah dan peran sebagai ibu rumah tangga atau sebagai orangtua ketika ia memiliki anak . Penelitian ini sejalan dengan penelitian yang dilakukan Sabria didapatkan bahwa pendidikan yang terbanyak adalah perguruan tinggi dengan jumlah 30 orang ibu postpartum $(53,6 \%){ }^{10,12}$

Tabel 12. Analisis Data Antara Pekerjaan Dengan Postpartum Blues

\begin{tabular}{|c|c|c|c|c|c|c|}
\hline \multirow{3}{*}{ Pekerjaan } & \multicolumn{4}{|c|}{ Postpartum blues } & \multirow{2}{*}{\multicolumn{2}{|c|}{ Nilai }} \\
\hline & \multicolumn{2}{|c|}{$\mathrm{Ya}$} & \multicolumn{2}{|c|}{ Tidak } & & \\
\hline & $\mathrm{N}$ & $\%$ & $\mathrm{~N}$ & $\%$ & $\mathrm{P}$ & OR \\
\hline Tidak Bekerja & 5 & $31,3 \%$ & 11 & $68,8 \%$ & & 10,909 \\
\hline Bekerja & 1 & $4 \%$ & 24 & $96 \%$ & 0,026 & $\begin{array}{l}(1,135- \\
104,807)\end{array}$ \\
\hline Total & 6 & $14,6 \%$ & 35 & $\begin{array}{c}85,4 \\
\%\end{array}$ & & \\
\hline
\end{tabular}

Pada tabel 12 didapatkan dari 41 ibu postpartum sebagian besar yang mengalami postpartum blues yaitu tidak bekerja sebanyak 5 responden $(31,3 \%)$. Dengan nilai $\mathrm{p}$ sebesar 0,026 yang menunjukkan bahwa adanya hubungan antara hubungan pekerjaan dengan postpartum blues. Ibu dengan tidak bekerja mempunyai kemungkinan 10,909 kali mengalami postpartum blues. Wanita yang bekerja dapat mengalami postpartum blues disebabkan adanya konflik peran ganda yang menimbulkan masalah baru bagi wanita tersebut. Hal ini sejalan dengan penelitian yang dilakukan Sabrian didapatkan hasil penelitian bahwa yang terbanyak adalah bekerja dengan jumlah 29 orang ibu postpartum $(51,8 \%){ }^{10,13}$ 
Tabel 13. Analisis Data Antara penghasilan Kejadian Postpartum Blues.

\begin{tabular}{|c|c|c|c|c|c|c|}
\hline \multirow{4}{*}{ Penghasilan } & \multicolumn{4}{|c|}{ Postpartum blues } & \multirow{3}{*}{\multicolumn{2}{|c|}{ Nilai }} \\
\hline & \multirow{2}{*}{\multicolumn{2}{|c|}{$\mathrm{Ya}$}} & \multirow{2}{*}{\multicolumn{2}{|c|}{ Tidak }} & & \\
\hline & & & & & & \\
\hline & $\mathrm{N}$ & $\%$ & $\mathrm{~N}$ & $\%$ & $\mathrm{P}$ & OR \\
\hline$<\mathrm{UMR}$ & 4 & $57,1 \%$ & 3 & $42,9 \%$ & & 21,333 \\
\hline >UMR & 2 & $5,9 \%$ & 32 & $94,1 \%$ & 0,005 & $\begin{array}{l}(2,694- \\
168,929)\end{array}$ \\
\hline Total & 6 & $14,6 \%$ & 35 & $85,4 \%$ & & \\
\hline
\end{tabular}

Pada tabel 13 didapatkan dari 41 ibu postpartum sebagian besar yang mengalami postpartum blues yaitu yang memiliki penghasilan <UMR sebanyak 4 responden $(57,1 \%)$. Dengan nilai $\mathrm{p}$ sebesar 0,005 yang menunjukkan bahwa ada hubungan antara penghasilan dengan kejadian postpartum blues. Ibu dengan <UMR mempunyai kemungkinan 21,333 kali mengalami postpartum blues. Kondisi ekonomi seringkali membuat psikologi ibu terganggu. Pada keluarga yang mampu mengatasi pengeluaran untuk biaya perawatan ibu selama persalinan, serta tambahan dengan hadirnya bayi yang baru dilahirkan mungkin hampir tidak merasakan beban keuangan sehingga tidak mengganggu proses transisi menjadi orang tua. Akan tetapi keluarga yang menerima kelahiran seorang bayi dengan suatu beban finansial dapat mengalami peningkatan stres, stres ini bisa mengganggu perilaku orang tua akan menjadi lebih sulit. Penelitian sebelumnya yang dilakukan Ibrahim mengatakan bahwa postpartum blues sebagian pada responden yang memiliki status ekonomi kurang yaitu sebanyak 11 responden $(37,9 \%) .{ }^{8,14}$

\section{SIMPULAN DAN SARAN Simpulan}

Berdasarkan hasil penelitian distribus frekuensi karakteristik responden berdasarkan kejadian postpartum blues didapatkan ibu yang mengalami postpartum blues berjumlah 6 responden $(14,6 \%)$ dan ibu yang tidak mengalami postpartum blues berjumlah 35 responden $(85,4 \%)$. Sehingga diketahui bahwa dari 41 ibu postpartum sebagian besar tidak mengalami postpartum blues (normal).
Sebagian besar karateristik responden umur 21-35 tahun, multipara, pervaginam, pendidikan rendah, bekerja, berpenghasilan $>$ UMR.

\section{Saran}

\section{Bagi masyarakat}

Masih banyak masyarakat yang belum mengetahui tentang postpartum blues dan bahayanya postpartum blues bila tidak ditangani dengan baik maka diharapkan masyarakat bisa lebih banyak mencari informasi tentang postpartum blues kepada tenaga medis.

\section{Bagi Tenaga Medis}

Bagi tenaga medis diharapkan untuk lebih memberikan pengetahuan kepada calon ibu ataupun ibu postpartum tentang postpartum blues. Salahsatu caranya dengan memberikan penyuluhan kepada calon ibu ataupun ibu postpartum beserta keluarganya (terutama suami) tentang perubahan psikologis yang terjadi pada ibu postpartum agar bisa merawat diri dan bayinya dan bagi keluarga dapat memberikan dukungan emosional yang baik.

\section{Bagi Peneliti Selanjutnya}

Diharapkan bagi peneliti berikutnya bisa meneliti hubungan antara postpartum blues dengan variabel yang akan diteliti dan bisa lebih menggali lebih luas lagi tentang faktor apa saja yang lebih banyak memberikan pengaruh terhadap kejadian postpartum blues. Dan dikaji lagi perihal isi dari kuesioner dari EPDS (Edinburg Postpartum Depression Scale).

\section{UCAPAN TERIMA KASIH}

Terimakasih kepada dr.Woro Pramesti, Sp.KJ selaku penguji saya, dr. Fonda Octarianingsih Shariff, Sp.OG Selaku pembimbing I saya, dr. Festy Ladyani, M.Kes 
Selaku pembimbing II saya., Tim skripsi Fakultas Kedokteran Universitas Malahayati, Dan yang terakhir yang saya sayangi ayah saya H.Suyanto, ST., MT ibu saya Drs. Nurhayati, S.Pdi

\section{REFERENSI}

1. Solekah Ma. Asuhan Kebidanan Pada Ibu Nifas Ny. "S" Dengan Bendungan Asi Di Bpm Ny. Rukhayati Desa Pulosari Kecamatan Karangtengah Kabupaten Demak (Doctoral Dissertation, Fakultas Kedokteran Unissula).

2. Nirwana Ab. Psikologi Ibu, Bayi Dan Anak. Yogyakarta: Nuha Medika. 2011.

3. Mansur H, Budiarti T. Psikologi ibu dan anak 2014.

http://journal.unnes.ac.id/sju/index.php/dcp/article /view/4441

4. Ishikawa N, Goto S, Murase S, Kanai A, Masuda T, Aleksic B, Usui H, Ozaki N. Prospective study of maternal depressive symptomatology among Japanese women. Journal of psychosomatic research. 2011 Oct 1;71(4):264-9.

5. Rubertsson C, Börjesson K, Berglund A, Josefsson A, Sydsjö G. The Swedish validation of Edinburgh postnatal depression scale (EPDS) during pregnancy. Nordic journal of psychiatry. 2011 Dec 1;65(6):414-8.

6. Depkes RI. Kehamilan dengan masalah psikologi 20088https://www.neliti.com/publications/18878 6/perbandingan-kejadian-post-partum-blues-padaibu-post-partum-dengan-persalinan-n

7. Yuliani DI, Yuliani F. Pengaruh Faktor Psikososial Dan Cara Persalinan Terhadap Terjadinya Postpartum Blues Pada Ibu Nifas (Studi Di Ruang Nifas Rsud Ra Bosoeni
Mojokerto). Hospital Majapahit (Jurnal Ilmiah Kesehatan Politeknik Kesehatan Majapahit Mojokerto). $2014 \mathrm{Feb}$ 10;6(1).

8. Bobak IM, Lowdermilk DL, Jensen MD, Perry SE. Buku ajar keperawatan maternitas. Jakarta: EGC. 2005.

9. Henshaw C. Mood disturbance in the early puerperium: a review. Archives of women's mental health. 2003 Aug 1;6(2):sIbrahim F, Ikhsan M. Faktor-Faktor yang Berhubungan Dengan Depresi Postpartum di RSIA Pertiwi Makassar Tahun 2012.

10. Priyanti S. Pengaruh Faktor Psikososial Dan Cara Persalinan Terhadap Terjadinya Postpartum Blues Di Rsud Ra. Basoeni Mojokerto (Doctoral Dissertation, Universitas Airlangga).

11. Utami Vw. Hubungan Dukungan Suami Terhadap Postpartum Blues Pada Ibu Nifas Di Bps Amrina, Amd. Keb Kelurahan Ganjar Asri Kecamatan Metro Barat Kota Metro Tahun 2016. Jurnal Kebidanan Malahayati. 2016;2(4).

12. Fatmawati DA. Faktor risiko yang berpengaruh terhadap kejadian postpartum blues. Eduhealth. 2015 Sep 1;5(2).

13. Jardri R, Pelta J, Maron M, Thomas P, Delion P, Codaccioni X, Goudemand M. Predictive validation study of the Edinburgh Postnatal Depression Scale in the first week after delivery and risk analysis for postnatal depression. Journal of affective disorders. $2006 \mathrm{Jul}$ 1;93(1-3):169-76.

14. Ibrahim F, Ikhsan M. Faktor-Faktor yang Berhubungan Dengan Depresi Postpartum di RSIA Pertiwi Makassar Tahun 2012. 